\title{
Cenas de um ensino de Desenho: reflexões metodológicas para a escrita da história
}

\author{
Scenes from a teaching of Drawing: \\ methodological issues for the writing of history
}

\section{Rosilene Beatriz Machado ${ }^{[a]}$, Cláudia Regina Flores ${ }^{[b]}$}

[a] Mestranda do Programa de Pós-Graduação em Educação Científica e Tecnológica pela Uni-versidade Federal de Santa Catarina (UFSC), Florianópolis, SC - Brasil, e-mail: rosibmachado@gmail.com

[b] Professora do Departamento de Metodologia de Ensino e do Programa de Pós-Graduação em Educação Científica e Tecnológica pela UFSC, pesquisadora do CNPq nível 2, Florianópolis, SC Brasil, e-mail: crf@mbox1.ufsc.br

\section{Resumo}

Este artigo explora a história da disciplina de Desenho, situando-se no âmbito do seu ensino. O objetivo é apresentar e discutir questões teórico-metodológicas para a escrita de uma história do ensino de Desenho a partir de cenas. A pesquisa acontece numa instituição escolar - o Colégio de Aplicação da Universidade Federal de Santa Catarina. Considera-se o período entre o início da década de 1960 até 2004, e as fontes para análise são tanto documentos oficiais quanto escolares que dão diretrizes a essa disciplina, bem como entrevistas com professores. As cenas do ensino do Desenho são construídas a partir dos depoimentos 
orais, gerando uma narrativa histórica. Enfim, reflete-se sobre as potencialidades e fragilidades desse modo de construção de escrita acerca da história da disciplina de Desenho.

Palavras-chave: História das disciplinas escolares. História do desenho. Ensino de desenho.

\section{Abstract}

This article is about the history of Drawing subject, considering the teaching of this discipline. The aim is to present and discuss theoretical and methodological approaches to writing a history of the teaching of Drawing from scenes. The research is performed in an educational institution - the College of the Federal University of Santa Catarina. We consider the period between the early 1960s and 2004. The sources for analysis are both official and school documents that give guidelines for this discipline as well as interviews with teachers. The scenes of the teaching of design are built based on oral testimony, creating a historical narrative. Finally, we reflect on the strengths and weaknesses of this mode of construction of the writing Drawing's history.

Keywords: History school subjects. History of drawing. Teaching drawing.

\section{Discutindo a temática de pesquisa}

A disciplina de Desenho esteve constituída como componente curricular obrigatório no ensino básico brasileiro por cerca de 30 anos, de 1930 a 1960. Contudo, na década de 1960, a Lei de Diretrizes e Bases da Educação (LDB), Lei 4.024 de 1961 (BRASIL, 1961), conferiu novos rumos ao ensino de Desenho no Brasil. A partir de então, a disciplina começou a experimentar certo desprestígio em meio aos documentos educacionais oficiais, passando a figurar como disciplina obrigatória complementar. Essa situação agravou-se com a promulgação da LDB 5.692/71 (BRASIL, 1971), que tornou o ensino de Educação Artística obrigatório no ensino básico, enquanto ao Desenho coube mais uma vez compor a parte diversificada do currículo. 
Atualmente, na LDB 9.394/96 (BRASIL, 1996), o Desenho não encontra no ensino fundamental e médio espaço como disciplina curricular obrigatória, tampouco como disciplina optativa. Também os Parâmetros Curriculares Nacionais (PCNs, 1998) para o ensino de Artes, do $6^{\circ}$ ao $9^{\circ}$ ano, não fazem qualquer referência à disciplina de Desenho. Nos PCNs destinados ao ensino de Matemática para esses mesmos anos, encontram-se alguns poucos indicativos, porém o Desenho aparece servindo apenas como auxiliar na conceituação dos assuntos. Além do que, para além da tímida inserção do Desenho nos PCNs de Matemática, vale destacar que as orientações ali contidas não implicam necessariamente sua concretização na sala de aula.

Isso nos remete a algumas reflexões e indagações. Presenciamos um momento em que é forte "a ilusão ou crença de que os softwares e o computador solucionarão os problemas de composição, decomposição e usos da forma com criatividade e inovação, em tempos de realidade de um mercado competitivo" (TRINCHÃO, 2008, p. 46). De fato, a "nova geração" de profissionais ligados à área gráfica sabe muito bem usar as ferramentas eletrônicas de Desenho, e são inquestionáveis as potencialidades dos diversos softwares existentes. Todo esse aparato tecnológico parece por si só justificar a ausência do ensino de Desenho nos moldes tradicionais (com régua e compasso). Mas até que ponto isso é válido se tais profissionais não souberem usar a linguagem gráfica do Desenho para aplicá-la corretamente e ter domínio sobre os programas computacionais?

O que nos remete mais além, ou seja, o Desenho, por possuir um caráter interdisciplinar, é relevante para a formação socioeducacional e cidadã, proporcionando o desenvolvimento de habilidades visomotoras e cognitivas no sujeito. Por meio do Desenho é que se revelam ideias, materializam-se e socializam-se gostos e desejos de criação.

Trinchão (2008, p. 19) argumenta que a ausência de atividades ligadas ao Desenho

implica em falências no desenvolvimento cognitivo, que naturalmente já envolvem os campos da Arte, Técnica e da Ciência, como capacidade observativa, criatividade, habilidade motora e visual, dentre outras, e, 
consequentemente, em atraso no investimento em cultura e formação técnico-científica.

Ainda segundo a autora, o Desenho, como conhecimento científico, e o cotidiano (entendendo-o como movimento de construção e experimento gerado no dia a dia para suprir as necessidades de sobrevivência humana), quando operados no âmbito escolar, "estabelecem um embate entre saberes que se inter-relacionam contraditoriamente e provocam contradições e rupturas, promovendo assim uma relação dialética na recriação didática e nos efeitos desse saber sobre o profissional" (TRINCHÃO, 2008, p. 19).

Assim sendo, partindo da realidade presente e tomando os questionamentos levantados, nossa intenção é associar-se a tais problemáticas, porém, sob as lentes da história, questionando sobre como e em que condições a disciplina de Desenho estabeleceu-se, em outros tempos, como prática escolar. O que queremos é situar-nos no intramuros da escola, voltar nosso olhar para dentro dela e direcionar nosso interesse à realidade concreta do ensino nos estabelecimentos e ao que entendemos por cultura escolar

um conjunto de normas que definem conhecimentos a ensinar e condutas a inculcar, e um conjunto de práticas que permitem a transmissão desses conhecimentos e a incorporação desses comportamentos (JULIA, 2001, p. 10).

Em outras palavras, perguntar como as disciplinas funcionam a fim de "encontrar na própria escola o princípio de uma investigação e de uma descrição histórica específica” (CHERVEL, 1990, p. 184). É levado em conta que uma disciplina escolar é constituída por uma combinação, em proporções variáveis, de um ensino de exposição, de exercícios, de práticas de incitação e de motivação e de um corpo de testes, provas e exames que lhe dão legitimidade e validação (CHERVEL, 1990, p. 207). Ainda, compreendemos que uma disciplina não se restringe às práticas docentes da aula, "mas também às grandes finalidades que presidiram sua constituição e o fenômeno de aculturação de massa que ela determina" (CHERVEL, 1990, p. 184). 
Vale destacar que um estudo histórico desloca a análise do "como ensinar" para "por que ensinar", questionando-se não o que somos, mas como chegamos a ser o que somos, para, a partir daí, podermos contestar nossa condição. Com um deslocamento dessa ordem, novos olhares se abrem ao que nos é dado como naturalizado e inquestionável. Trata-se, portanto, de construir uma história de uma disciplina escolar, cujos conteúdos são seu componente central, mas colocando seu ensino em relação com as finalidades às quais ele está designado e com os resultados concretos que ele produz (CHERVEL, 1990, p. 187).

Para tanto, a história que se pretende será entendida como uma operação, ou seja, a relação entre um lugar, procedimentos de análise e a construção de um texto (CERTEAU, 2007, p. 66). Da história como operação insurge o "fazer história" como uma prática. Sob esse viés, o fato histórico não será concebido como algo dado, passível de ser desvendado em um texto que por hora apresenta-se. Ele será construído de acordo com as problemáticas que a pesquisa assume, de forma que "de resíduos, de papéis, de legumes, até mesmo das geleiras e das 'neves eternas', o historiador faz outra coisa: faz deles a história” (CHERVEL, 1990, p. 179). O passado não é, pois, “um 'dado', mas um produto" (CHERVEL, 1990, p. 180).

Tecidas essas considerações, é conveniente ater-nos por alguns momentos aos elementos que, entrecruzados, constituem a trama histórica da narrativa que intentamos construir: o objeto, o lugar de investigação, o período e o material de análise. O objeto de nosso trabalho é o ensino da disciplina de Desenho. A investigação acontece no interior de uma instituição escolar: o Colégio de Aplicação da Universidade Federal de Santa Catarina. O período a ser investigado está compreendido entre o início da década de 1960 até 2004. Por fim, debrucemo-nos sobre os materiais de análise. Para Certeau (2007, p. 83),

tudo começa com o gesto de separar, de reunir, de transformar em documentos certos objetos distribuídos de outra maneira. Esta nova distribuição cultural é o primeiro trabalho. Na realidade, ela consiste em produzir tais documentos, pelo simples fato de recopiar, transcrever 
ou fotografar estes objetos mudando ao mesmo tempo o seu lugar e o seu estatuto. Este gesto consiste em 'isolar' um corpo, como se faz em física, e em 'desfigurar' as coisas para constituí-las como peças que preencham lacunas de um conjunto, proposto a priori.

Um dos documentos tratados por nós como fontes históricas faz parte, então, dos documentos oficiais que nos permitam, minimamente, cumprir com um dos objetivos da história de uma disciplina escolar, qual seja, "analisar um conjunto de normas que definem conhecimentos a ensinar e condutas a inculcar" (JULIA, 2001, p. 10), e, dessa forma, determinar as finalidades que lhe correspondem (CHERVEL, 1990, p. 188). Além destes, com a convicção de que não podemos "nos deixarmos enganar inteiramente pelas fontes, mais frequentemente normativas que lemos" (JULIA, 2001, p. 15), os textos normativos nos reenviarão às práticas, donde se abre uma gama de outros documentos a serem investigados: diários de classe, planejamentos, avaliações e listas de exercícios, bem como os livros didáticos mais utilizados pelos professores de Desenho do colégio, por meio dos quais buscaremos evidenciar os "conteúdos ensinados, os exercícios e as provas de natureza quantitativa que asseguram o controle das aquisições" (JULIA, 2001, p. 34).

Finalmente, com o entendimento de que "normas e práticas não podem ser analisadas sem se levar em conta o corpo profissional dos agentes que são chamados a obedecer essas ordens e, portanto, a utilizar dispositivos pedagógicos encarregados de facilitar sua aplicação" (JULIA, 2001, p. 11), uma nova fonte será agregada a esse conjunto de materiais: o testemunho de 12 professores que contribuem com a história do ensino de Desenho no Colégio de Aplicação da UFSC.

A partir dessas últimas fontes - os depoimentos orais -, este trabalho será construído. E isso se dá sob a perspectiva de que histórias são sempre estórias. Cada qual é uma construção individual e, dessa forma, única. A história que pretendemos contar, por sua vez, terá sua unicidade revelada em uma composição multifacetada, organizada de acordo com nosso olhar sobre os documentos de que dispomos. Essa história será, então, narrada sob diferentes perspectivas, a partir de variadas fontes 
escritas e orais. Será narrada, especificamente, sob as "verdades particulares" dos professores entrevistados, aliadas às análises sobre as problemáticas que essas "verdades reveladas" trazem à tona.

Cada entrevista será apresentada em nosso trabalho sob a perspectiva do depoente, ou seja, narrada em primeira pessoa. Não queremos com essa estrutura construir uma história que seja resultado do somatório de histórias particulares. Ao contrário, objetivamos, por meio da apresentação de uma pluralidade e diversidade de versões, destacar problemáticas emergentes nessas fontes a fim de que estas sejam analisadas à luz das outras fontes selecionadas. Assim, as entrevistas, juntamente com nossas análises, serão organizadas em cenas, dispostas de forma a evidenciar a vida e a morte da disciplina de Desenho no Colégio de Aplicação da UFSC.

Este artigo, portanto, objetiva apresentar uma das muitas cenas que a pesquisa se propõe realizar ${ }^{1}$, analisando as potencialidades e fragilidades desse modo de construir a pesquisa para a escrita de uma história da disciplina de Desenho.

\section{Construindo uma cena}

Como explicitado anteriormente, para estruturar a pesquisa, a ideia é ir compondo cenas. Essas cenas, por sua vez, serão constituídas por atos, resultantes do depoimento de um (ou mais) professor entrevistado, e de nossas análises que levantam uma problemática a partir do depoente. A título de ilustração, destacaremos a seguir a composição de uma das cenas construídas, intitulada $O$ nascimento.

A problemática emerge do seguinte trecho²:

1 Trata-se de uma pesquisa de mestrado iniciada em 2010, no Programa de Pós-Graduação em Educação Científica e Tecnológica da Universidade Federal de Santa Catarina, intitulada "Entre Vida e Morte: Memórias de um Ensino de Desenho", sob a orientação da professora Dra. Cláudia Regina Flores.

2 Trecho extraído do depoimento oral concedido em novembro de 2010, pelo prof. Romeu Augusto de Bezerra Albuquerque, atual Diretor Geral do Colégio de Aplicação da UFSC. 
Em 2004 acabou o desenho no Colégio de Aplicação e de lá pra cá nunca mais foi reintroduzido na grade. Eu acho que... Não sei... Agora uma opinião de metido... A pulverização, cada um criou desenho de alguma coisa, adjetivou o desenho de alguma coisa, acabou fracionando... Não tinha mais o que fazer. Afinal de contas, o que seria o desenho na escola? O que seria o conteúdo programático ou o currículo de desenho da escola básica? Aí cada um oferecia um negócio diferente... Mas essa perspectiva não era da escola, era do profissional que ela conseguia... Isso aconteceu muito com a gente aqui!

A partir do trecho destacado, percebe-se que uma das questões que permearam a exclusão da disciplina de Desenho da grade curricular do Colégio de Aplicação da UFSC foi a indefinição quanto ao que seria essa disciplina em termos de conteúdo. Dessa forma, a cena $O$ nascimento foi construída considerando esse ponto específico, tomando o questionamento do professor sobre o que seria o conteúdo programático da disciplina de Desenho na escola.

O objetivo é, assim, mostrar ao leitor como o Desenho ganhou vida, constituindo-se em uma disciplina escolar. A seguir, vamos resumidamente esboçar o conteúdo dessa cena. Para tanto, deixemos o presente (e a morte) da disciplina de Desenho por alguns instantes. Voltemos-nos, pois, ao seu passado com o intuito de situar-nos em momentos históricos específicos, buscando compreender como o Desenho transformou-se em um saber a ensinar, direcionando essa compreensão especialmente para o Brasil.

\section{O nascimento: alguns encaminhamentos}

Apesar de já se perceber a prática de um ensino de Desenho no período medieval, em que ele era tido como um conhecimento prático, restrito às corporações de ofício ${ }^{3}$, não estão na Idade Média as raízes do que seria o Desenho como disciplina escolar. A organização desse saber

\footnotetext{
${ }^{3}$ As corporações eram associações de artesãos ou comerciantes que reuniam profissionais do mesmo ramo com o objetivo de combater o privilégio religioso.
} 
como objeto de ensino deu-se em função de algumas necessidades sociais que marcaram os séculos seguintes.

A primeira dessas necessidades pode ser considerada como a necessidade de uma representação realista de mundo que surgiu durante o Renascimento Italiano, nos séculos XIV a XVI. Tal necessidade veio pautada basicamente por três problemáticas emergentes nesse período: a retirada da Igreja do poder, que permitiu ao homem pensar o infinito para além das barreiras do céu; a descoberta da América, implicando um abandono dos mapas simbólicos e religiosos, característicos do período medieval, em busca de representações cartográficas geometrizadas; e o humanismo, implicando uma representação realista das pessoas, dos objetos e do espaço, obedecendo à forma, à ordem e à racionalidade (FLORES, 2007).

Essas problemáticas impulsionaram a criação de técnicas que dessem conta de representar no plano, de forma realista, o objeto que está no espaço. Assim, muitos artistas passaram a estudar a ciência da representação em perspectiva e escreveram diversos tratados sobre essa técnica. Entre eles, Leon Batista Alberti foi o primeiro a expor de maneira formal as ideias matemáticas que sustentavam a técnica da perspectiva. Dessa forma, a instauração da perspectiva como forma correta de representação do real gerou processos de ensino da técnica e da arte de desenhar. Isso pode ser percebido pelos diversos tratados escritos que tinham o objetivo não só de registrar os saberes dessa técnica, mas permitir que artesãos, pintores, engenheiros e arquitetos aprendessem os conceitos dessa nova forma de representação.

Outro elemento que contribuiu para a sistematização do saber em Desenho foi a necessidade de fortificação. A partir do século XIV começaram a aparecer as primeiras armas de fogo para serem utilizadas na guerra. A artilharia evoluiu para o canhão nos séculos seguintes, e a partir do século XVII influiu fortemente sobre as formas de construir fortificações. Com o acelerado desenvolvimento dos canhões, novas questões emergiram em torno da necessidade de defesa, fazendo da "arte de bem fortificar" um negócio de Estado. Nesse contexto, os tratados sobre fortificação multiplicaram-se com o objetivo de sistematizar os conhecimentos sobre o assunto, tomando a Geometria e o Desenho como base. 
No domínio militar era preciso, então, que a imagem possibilitasse o máximo de visibilidade, bem como a medida das coisas a partir de sua escala. Logo, outros procedimentos que correspondessem a essa forma de visibilidade ganharam seu meio de aplicabilidade, como a perspectiva paralela, que possibilitava perceber uma composição geométrica na imagem de um mapa, de um plano de ataque ou de um projeto de construção. Por esse motivo, a técnica da perspectiva, em especial a militar ou cavaleira, os desenhos de perfil e a voo de pássaro, foram privilegiados nos tratados dos arquitetos militares na Europa, constituindo-se na forma usual de representação (FLORES, 2007).

Esses novos procedimentos que surgiram para representar eram, na verdade, múltiplos da técnica da perspectiva central, desenvolvida por Alberti no século XV. Vê-se, portanto, como uma nova necessidade social fez uso do saber em Desenho, constituído no âmbito das artes, em um espaço completamente diferenciado: o espaço da arquitetura militar. Os tratados militares, particularmente, surgidos da "arte da fortificação" nos séculos XVI e XVII foram um propulsor do que mais tarde seria o Desenho como disciplina escolar. O século seguinte, no bojo do desenvolvimento industrial, trouxe a necessidade de produção, e com ela vieram novas contribuições para a organização desse saber.

No século XVIII, Gaspard Monge ${ }^{4}$ desenvolveu uma ciência, conhecida como Geometria descritiva, que permitia representar sobre um plano as formas do espaço, de modo a poder resolver, com o auxílio da Geometria plana, os problemas em que se consideravam as três dimensões. Essa possibilidade de representar corretamente sobre um plano "viabilizou a industrialização da sociedade ocidental através da

4 Segundo Belhoste (1998, p. 20), Gaspard Monge (1746-1818) foi professor da L'École de Mézières, que tinha a função de assegurar a formação teórica de engenheiros de fortificações. Seu principal objetivo era resolver problemas de como determinar melhores posições para fugir do fogo cruzado da artilharia inimiga. Monge passou a utilizar o corte de pedras para introduzir os alunos aos métodos geométricos de Desenho necessários a um engenheiro. Ele transformou, assim, os procedimentos da estereotomia (corte de pedras e madeira) em um "corpus de doutrina", ao qual ele deu mais tarde o nome de Geometria descritiva. 
produção sistemática de peças e conjuntos mecânicos, fortificações militares, edifícios, pontes, etc." (SOARES, 2007, p. 6).

Nesse meio técnico, envolvido às exigências da produção em série dos objetos manufaturados, as perspectivas paralelas, em especial a cavaleira, novamente ganharam destaque. Passou-se a requerer do marceneiro, do arquiteto ou do engenheiro, um desenho que, além da visibilidade do todo do objeto, proporcionasse a informação exata das suas dimensões e a ideia precisa de seu volume, o que deu origem ao desenho técnico.

Segundo Trinchão (2008, p. 240), o desenho, tomado como objeto de ensino, tem suas origens nos tratados de artistas, artesãos e principalmente, nos manuscritos de professores de escolas militares. Esse conhecimento gradativamente foi inserindo-se no meio escolar, elementar e secundário, a partir de uma "transposição de conteúdos mais amplos que faziam parte da Matemática, como os elementos básicos da Geometria Descritiva”.

No Brasil, é a partir do século XVIII, com a urgência de Portugal em proteger e defender suas terras de além-mar, que se dão as primeiras iniciativas de um ensino de ciências, especialmente de Matemática e Desenho, a fim de formar pessoal capacitado para trabalhos com fortificações militares. A chegada da corte portuguesa ao país em 1808 promoveu significativas mudanças no ensino brasileiro por meio da criação da Academia Real Militar em 1811. Foi a partir da criação da Academia que se consolidou "o ensino sistemático das Matemáticas, das Ciências e da técnica no Brasil, no início do século XIX" (ZUIN, 2001, p. 64), sendo que o Desenho passou a ser fortemente valorizado na formação do engenheiro militar brasileiro.

Assim, é do interior das escolas militares que o Desenho ganhará visibilidade no Brasil. Porém, é importante ressaltar que o ensino militar era destinado unicamente aos filhos de nobres, aos abastados provenientes da alta aristocracia brasileira, constituindo uma espécie de curso superior naquela época. Será somente após a independência do país que o ensino de Desenho vai ser expandido em virtude dos exames preparatórios.

A instituição da instrução oficial no Brasil iniciou-se logo após sua independência, a partir da Carta Lei de 25 de março de 1824. A carta versava, entre outros assuntos, "sobre a garantia da gratuidade da Instrução 
primária a todo cidadão e sobre o direito ao acesso aos elementos das Ciências, Belas-Artes e Letras, através dos Colégios e Universidades" (TRINCHÃO, 2008, p. 173). A partir dessa carta, em 1827 foi outorgada a Lei de 15 de novembro, que criou as primeiras escolas primárias do Brasil. Definida a escolarização primária, "o estabelecimento dos cursos superiores no Brasil impõe a obrigação de definir quais deverão ser os pré-requisitos para ingresso do futuro médico, advogado e engenheiro" (VALENTE, 2007, p. 113). A partir de então, deu-se um processo de transformação, principalmente no ensino secundário, que se encontrava fragmentado em forma de aulas régias provenientes da Reforma Pombalina ${ }^{5}$.

Assim, a partir do Ato Adicional de 1834 começaram a ser tomadas providências com o intuito de organizar o ensino secundário brasileiro, quando foram criados as Escolas Normais, os Liceus Provinciais e ainda o Colégio Pedro II em 1837. O Desenho, como conhecimento a ser ensinado, fez parte do quadro de disciplinas dos liceus provinciais e das escolas normais criados nesse período e também do Colégio Pedro II.

Foi no bojo da criação dessas instituições que o Desenho começou a sair da esfera privada dos ateliês e das escolas militares, e passou a fazer parte da cultura escolar geral. Isso ocorreu por conta dos professores militares convocados para o ensino nos preparatórios, o que acabou difundindo a escolarização técnico-militar desenvolvida nas academias para a esfera pública. Essa difusão deu-se tanto por meio dos liceus que se espalharam pelo país, garantindo a formação do candidato ao ensino superior, quanto por meio das escolas normais, responsáveis por formar o professorado que atuaria na instrução primária.

Os rumores da necessidade de desenvolvimento da indústria brasileira, ao fim do século XIX, despertaram um interesse maior em investimento na educação técnica, que aqui já existia precariamente. Nesse contexto,

${ }^{5}$ Essa reforma, instituída no século XVIII, desmantelou o ensino jesuítico existente, criando as chamadas Aulas Régias. Estas eram aulas de disciplinas isoladas, ministradas em locais diferentes e tinham o objetivo de sanar os problemas com a educação, provenientes da expulsão dos jesuítas do país. 
destacou-se a figura de Rui Barbosa ${ }^{6}$, para o qual o Desenho seria a sustentação de toda a industrialização do país. Então deputado, ele chefiou uma comissão que apresentou um projeto para a reformulação da instrução primária, secundária e também superior do Brasil. Esse projeto foi divulgado em 1882, e "nessa nova proposta, as disciplinas Desenho Linear e Elementos de Música e Ginástica, passaram a compor o quadro de saberes destinados ao ensino primário" (TRINCHÃO, 2008, p. 372). O Desenho passou a figurar também em todos os anos de todos os cursos dos liceus.

Zuin (2001, p. 70) destaca que Rui Barbosa preocupava-se muito com a situação do ensino em nosso território. Ele argumentava que o Brasil encontrava-se em extrema desvantagem em relação ao desenvolvimento econômico e educacional de países como Alemanha, Áustria, Estados Unidos, França, Inglaterra e Suíça, "aconselhando, então, a elaboração de um sistema nacional de educação". Logo, "é Rui Barbosa que imprime, definitivamente, o Desenho como um saber escolar necessário para o desenvolvimento industrial. Além disso, o fato de já existirem publicações nacionais na área facilitava o ensino/aprendizagem do Desenho" (ZUIN, 2001, p. 70).

No entanto, os pareceres de Rui Barbosa sobre a educação no país não chegaram a ser discutidos na Câmara dos Deputados, sendo que suas propostas não foram efetivadas. Ainda assim, o ensino de Desenho passou a ser "mais valorizado a partir das últimas décadas do século XIX, quer seja influenciado pela França, quer pelos pareceres de Barbosa, visando o progresso do país" (ZUIN, 2001, p. 71).

Foi então, a partir da década de 1930, que o Desenho ganhou espaço, pelo menos no âmbito da lei, no cenário público educacional, no sentido de uma oficialização de seu ensino a todos os segmentos educacionais. O momento pós-segunda guerra mundial impôs ao Brasil sérias restrições às importações, levando à implementação da indústria nacional. Na esteira de tais transformações, a Reforma Francisco Campos, em

\footnotetext{
${ }^{6}$ Rui Barbosa de Oliveira, natural de Salvador, BA, viveu de 1849 a 1923. Foi um jurista, político e diplomata brasileiro, formado pela Faculdade de Direito do Largo de São Francisco, tendo exercido os cargos de deputado, senador e ministro em nosso país.
} 
1931, buscou organizar e uniformizar os conteúdos e métodos de ensino nas escolas oficiais em todo o país. Essa Reforma oficializou o ensino de Desenho no currículo da escola básica brasileira, em que passou a figurar em todas as séries do ensino secundário, tanto do ciclo fundamental, quanto do ciclo complementar ${ }^{7}$. Esse ensino foi dividido em quatro modalidades: Desenho do natural, Desenho decorativo, Desenho geométrico e Desenho convencional.

Na década de 1940, entre 1942 e 1946, ocorreu uma nova reforma educacional, conhecida como Reforma Capanema. Essa reforma estabeleceu três modalidades de Desenho para o nível ginasial ${ }^{8}$ : Desenho do natural, Desenho decorativo, Desenho geométrico, incluindo nas últimas séries noções de Desenho projetivo e de perspectiva. Para o curso colegial e científico, determinou que na primeira e na segunda séries deveriam ser contemplados o ensino do Desenho do natural, Desenho geométrico e projetivo, decorativo e convencional. Para a terceira série, estariam reservados o Desenho do natural, projetivo e técnico.

Após a Reforma Capanema, em 1951, os programas para o curso ginasial e científico foram novamente redefinidos pelas Portarias n. 966 e n. 1045. De acordo com Nascimento (1999), pouca coisa se alterou em relação à reforma anterior. Talvez a maior diferença tenha sido em relação ao Desenho geométrico, que agora deveria ter uma finalidade mais instrutiva do que educativa, pois deveria visar à aquisição de conhecimentos indispensáveis para outras áreas, notadamente a Matemática, da qual deveria tornar-se

\footnotetext{
7 A partir da Reforma Francisco Campos, em 1931, o curso secundário foi dividido em um ciclo fundamental (cinco séries) e um ciclo complementar (três séries). O primeiro visava à formação básica geral, e o segundo era considerado como preparatório ao ensino superior. O ciclo complementar era divido ainda em três ramos: Humanidades (para os estudos jurídicos); Medicina, Farmácia e Odontologia; e Engenharia e Arquitetura.

${ }^{8}$ A Reforma Capanema organizou o ensino primário, secundário, bem como o ensino industrial, comercial, normal e agrícola. O ensino secundário continuou dividido em dois ciclos, mas ganhou uma configuração diferente: o 1 ำ ciclo, ou curso ginasial, teve a duração alterada de cinco para quatro anos e o 20 ciclo, ou curso colegial, de dois para três anos, sendo que este foi subdividido em duas modalidades distintas, o clássico e o científico.
}

Rev. Diálogo Educ., Curitiba, v. 11, n. 34, p. 687-707, set./dez. 2011 
um auxiliar imediato. Ao que tudo indica, esse foi o último programa oficial de Desenho publicado pelo Ministério da Educação, em nível nacional.

Chegada a década de 1950, portanto, o Desenho estava instituído como disciplina escolar no currículo brasileiro, presente em todas as séries do ensino secundário. Apesar da estratificação experimentada pela disciplina, que se encontrava dividida em diversas modalidades, pode-se dizer que as décadas de 1930 a 1950 constituíram seus "anos de ouro" no Brasil, dada sua visibilidade em meio aos documentos educacionais oficiais. No entanto, a estabilidade alcançada entre essas décadas encontraria um terreno bastante arenoso nos anos seguintes. Alterações na legislação educacional começam a dar indícios de uma desvalorização de seu ensino. Novas mudanças virão com a Lei de Diretrizes e Bases de 1961. Mas essas já são questões para as próximas cenas.

\section{Sobre a proposta metodológica: potencialidades e fragilidades}

Assim como construímos a cena $O$ nascimento, as cenas seguintes trazem os depoimentos dos professores entrevistados, seguidas de nossas análises sobre as problemáticas levantadas em cada uma delas. A perspectiva é ir organizando os depoimentos de maneira a evidenciar os elementos de vida e morte do ensino da disciplina de Desenho no Colégio de Aplicação da UFSC. Isso significa, em certo sentido, construir, a partir da narrativa dos depoimentos, a história do ensino de Desenho nessa instituição de ensino. Nesse ponto, a construção de tal escrita histórica é possível na medida em que se lança mão do discurso oral, mas também do discurso oficial escrito para tecer análises históricas.

Assim, essa construção de uma narrativa histórica insere-se numa dinâmica de pensar a história como uma produção (CERTEAU, 2008). A prática histórica é tanto quanto prática científica na medida em que envolve a construção de objetos de pesquisa o uso de uma operação específica de trabalho e um processo de validação dos resultados obtidos. Ao historiador, no caso, o pesquisador, cabe levantar hipóteses e problematizando 
marcas do passado deixadas no presente elabora respostas às questões préviamente formuladas. Portanto, a fim tem-se um produto que passou por etapas, por uma operação historiográfica, como define Certeau (2008), pois, ao fabricarmos tal narrativa histórica, mediamos elementos distintos, tais como: um lugar temporal, espacial, social, cultural, institucional; uma disciplina feita de conceitos, regras, métodos; e uma escritura feita de estilos, gêneros, formas.

Por outro lado, na medida em que as problemáticas crescem e abrem pontos diversos, percebe-se que lidar com a história da disciplina de Desenho, tomando o ensino dessa disciplina como objeto de pesquisa, implica envolver outra gama de fontes, tais como os manuais didáticos, as provas de vestibulares, entre outros. Nesse sentido, a proposta torna-se ampla, necessitando do pesquisador um envolvimento maior de tempo e de pesquisa, ou fazer escolhas das problemáticas e fontes analisadas. Porém, como diz Albuquerque Júnior (2007, p. 29),

[...] não podemos optar por habitar a margem do objetivismo ou a margem do subjetivismo, a margem da natureza ou a margem da cultura, a margem da realidade ou a margem da construção discursiva da História, pois a História em seu acontecer articula e relaciona todos estes aspectos e a narrativa histórica também deve fazê-lo.

Sobre o método, a saber, partindo dos depoimentos orais para gerar problemáticas e construir uma narrativa histórica, há que se considerar a necessidade de uma discussão quanto aos aspecto teóricos e metodológicos que envolvem trabalhar com memórias, tomando-se cuidado para se ter uma clara conceitualização de memória e história. Aqui vale adiantar que as memórias não como discurso verdadeiro, prova ou reforço do argumento do pesquisador, para construir uma história oficial, verdadeira. Enfim, vale a pena terminar isso aqui com Albuquerque Júnior (2007, p. 207, grifo nosso), dizendo que "Na memória fica o que significa9; na História se ressignifica o que fica [...]"

${ }^{9}$ BOSI, E. Memória e sociedade: lembrança de velhos. 2. ed. São Paulo: Companhia das Letras, 1994. p. 1. 


\section{Considerações finais}

Por fim, cabe dizer que uma pesquisa histórica sobre o ensino da disciplina de Desenho, elaborada à luz dos olhos daqueles que viveram o processo, ressalta, especialmente, o interesse em contribuir com a formação do professor de Matemática. De um lado, uma narrativa literária toca mais sensivelmente o leitor que está fora da academia. Lê-se em reportagem da Folha de S. Paulo (CARIELLO, 2011) que o sociólogo Luis de Gusmão preconiza o retorno das humanidades nos trabalhos acadêmicos, colocando-se a favor de uma escrita mais livre, que dialogue com o senso comum, que privilegie a compreensão e que não ambicione o estabelecimento de leis científicas.

E, por outro lado, o Desenho, especificamente o Desenho geométrico, tem estreitas ligações com a Geometria, o que possibilitaria compreender muitas questões ligadas ao ensino e aprendizagem também de Matemática. De acordo com Wagner (1998), estando as construções geométricas cada vez mais ausentes dos currículos escolares, deve-se resgatá-las do esquecimento e apontar a sua importância no aprendizado da Geometria. Ainda, segundo D’Ambrósio (1983, p. 8-9),

em essência, a ação do matemático resulta na produção de mentefatos, enquanto a ação do artista resulta na produção de artefatos. O Desenho é aquela disciplina intelectual, aquela manifestação de ação, que se situa, privilegiadamente, entre o artefato e o mentefato. [...] A combinação Desenho Geométrico - onde inclui as construções geométricas, a perspectiva e a Geometria Descritiva - e Desenho Artístico é essencial para obter essa situação intermediária entre o mentefato e o artefato.

Não nos aprofundaremos nesse aspecto, no sentido de analisar quais contribuições efetivas o ensino de Desenho dispensa ao ensino de geometria, porém um trabalho histórico, tal qual o que pretendemos, deverá contribuir com essa discussão, já que evidenciará como se deu o ensino da disciplina de Desenho em tempos passados. Além disso, toda essa análise deverá apontar reflexões para o ensino de Desenho como área de conhecimento que possibilita a educação do olhar para a atual sociedade. 


\section{Referências}

ALBUQUERQUE JR., D. M. de. História: a arte de inventar o passado. Bauru: Edusc, 2007.

BELHOSTE, B. Représentation de l'espace ET géométrie de Dürer à Monge. La science à l'époque moderne. Bulletin de l'Association des historiens modernistes des universités, n. 21, p. 7-27, 1998.

BOSI, E. Memória e sociedade: lembrança de velhos. 2. ed. São Paulo: Companhia das Letras, 1994.

BRASIL. Decreto n. 19.890, de 18 de abril de 1931. Dispõe sobre a organização do ensino secundário. Diário Oficial da União, Rio de Janeiro, 1 maio 1931, ano 70, n. 101, p. 6945-6951. Disponível em: <http://www.histedbr.fae.unicamp.br/ navegando/fontes_escritas/5_Gov_Vargas/decreto\%2019.890-\%201931\%20reforma\%20francisco\%20campos.htm>. Acesso em: 23 jul. 2010.

BRASIL. Ministério da Educação e Saúde Pública. Portaria Ministerial s/n, de 30 de junho de 1931. Dispõe sobre os programas do curso fundamental do ensino secundário e instruções metodológicas - Desenho. Diário Oficial da União, Rio de Janeiro, 30 jul. 1931, ano 70, n. 178, p. 12423-12424.

BRASIL. Portaria Ministerial s/n, de 17 de março de 1936. Dispõe sobre os programas do curso complementar - Desenho. Diário Oficial da União, Rio de Janeiro, 19 mar. 1936, ano 75, n. 66, p. 5824-5825.

BRASIL. Decreto-lei n. 4.244, de 9 de abril de 1942. Das bases de organização do ensino secundário. Diário Oficial [da] República Federativa do Brasil, Poder Legislativo, Brasília, DF, 18 mar. 1931. Disponível em: <http://www2.camara. gov.br/legin/fed/declei/1940-1949/decreto-lei-4244-9-abril-1942-414155-retificacao-69216-pe.html>. Acesso em: 23 jul. 2010.

BRASIL. Portaria Ministerial n. 555, de 14 de novembro de 1945. Expede programas de Desenho e respectivas instruções metodológicas e determina sua execução no curso ginasial do ensino secundário. Diário Oficial da União, Rio de Janeiro, 22 nov. 1945, ano 84, n. 263, p. 17766-17769. 
BRASIL. Portaria Ministerial n. 10, de 4 de janeiro de 1946. Expede programas de Desenho e respectivas instruções metodológicas e determina sua execução nos cursos colegial e científico do ensino secundário. Diário Oficial da União, Rio de Janeiro, 14 jan. 1946, ano 85, n. 11, p. 609-611.

BRASIL. Portaria Ministerial n. 966, de 2 de outubro de 1951. Aprova programas para o curso secundário. In: BRASIL. Ministério da Educação e Saúde. Serviço de documentação. Programas do ensino secundário. São Paulo: Nacional, 1952. p. 50-52.

BRASIL. Portaria Ministerial n. 1045, de 14 de dezembro de 1951. Aprova os planos de desenvolvimento dos programas mínimos do curso secundário e respectivas instruções metodológicas. In: BRASIL. Ministério da Educação e Saúde. Serviço de documentação. Programas do ensino secundário. São Paulo: Nacional, 1952. p. 172-185.

BRASIL. Lei n. 4.024, de 20 de dezembro de 1961. Fixa as diretrizes e bases da educação nacional. Diário Oficial [da] República Federativa do Brasil, Poder Legislativo, Brasília, DF, 27 dez. 1961. p. 11429. Disponível em: <http://www. planalto.gov.br/ccivil_03/Leis/L4024.htm>. Acesso em: 20 jul. 2010.

BRASIL. Lei n. 5.692, de 11 de agosto de 1971. Fixa diretrizes e bases para o ensino de primeiro e segundo graus, e da outras providencias. Diário Oficial [da] República Federativa do Brasil, Poder Legislativo, Brasília, DF, 12 ago. 1971. p. 6377. Disponível em: <http://www6.senado.gov.br/legislacao/ ListaTextoIntegral.action?id=75576 >. Acesso em: 23 jul. 2010.

BRASIL. Lei n. 9.394/96, de 20 de dezembro de 1996. Estabelece as diretrizes e bases da educação nacional. Diário Oficial [da] República Federativa do Brasil, Poder Legislativo, Brasília, DF, 23 dez. 1996. p. 27833. Disponível em: <http://www6.senado.gov.br/legislacao/ListaTextoIntegral.action?id=75723>. Acesso em: 23 jul. 2010.

BRASIL. Secretaria de Educação Fundamental. Parâmetros Curriculares Nacionais: Artes $3^{\circ}$ e $4^{\circ}$ ciclos. Brasília: MEC/SEF, 1998.

CARIELLO, R. Fetiches conceituais: hora de pendurar o jaleco retórico. Folha de São Paulo, 27 março, 2011. 
CERTEAU, M. de. A escrita da história. 2. ed. Rio de Janeiro: Forense-Universitária, 2007.

CHERVEL, A. História das disciplinas escolares: reflexões sobre um campo de pesquisa. Teoria e Educação, Porto Alegre, n. 2, p. 177-229, 1990.

D’ AMBROSIO, U. Ensino de Desenho Geométrico em bases metodológicas renovadas. In: SIMPÓSIO NACIONAL DE GEOMETRIA DESCRITIVA E DESENHO TÉCNICO, 5., 1983, Bauru. Anais... Bauru: Simpósio Nacional de Geometria Descritiva e Desenho Técnico, 1983. p. 1-10.

FLORES, C. R. Olhar, saber, representar: sobre a representação em perspectiva. São Paulo: Musa, 2007.

JULIA, D. A cultura escolar como objeto histórico. Revista Brasileira de História da Educação, n. 1, p. 9-43, 2001.

NASCIMENTO, R. A. A função do desenho na educação. 1999. 216 f. Tese (Doutorado em Educação) - Faculdade de Filosofia e Ciências, Universidade de São Paulo, Marília, São Paulo, 1999.

SOARES, C. P. Uma abordagem histórica e científica das técnicas de representação gráfica.In: GRAPHICA2007-DESAFIODAERADIGITAL:ENSINOETECNOLOGIA, SIMPÓSIO NACIONAL DE GEOMETRIA DESCRITIVA E DESENHO TÉCNICO, 8., INTERNATIONAL CONFERENCE ON GRAPHICS ENGINEERING FOR ARTS AND DESIGN, 7., 2007, Curitiba. Anais... Curitiba: UFPR, 2007.

TRINCHÃO, G. M. C. O desenho como objeto de ensino: história de uma disciplina a partir dos livros didáticos luso-brasileiros oitocentistas. 2008. $496 \mathrm{f}$. Tese (Doutorado em Educação) - Universidade do Vale do Rio Sinos, São Leopoldo, RS, Brasil.

VALENTE, W. R. Uma história da matemática escolar no Brasil: 1730-1930. 2. ed. São Paulo: Annablume, 2007.

WAGNER, E. Construções geométricas. 2. ed. Rio de Janeiro: Sociedade Brasileira de Matemática, 1998. 
ZUIN, E. S. L. Da régua e do compasso: as construções geométricas como um saber escolar no Brasil. 2001. 211 f. Dissertação (Mestrado em Educação) - Faculdade de Educação, Universidade Federal de Minas Gerais, Belo Horizonte, 2001.

Recebido: 06/05/2010

Received: 05/06/2010

Aprovado: 25/10/2010 Approved: 10/25/2010 